\title{
Profil Ergonomis dan Proporsi Keluhan Muskuloskeletal pada Tenaga Kerja Bongkar Muat di Pelabuhan Bongkar Muat Kota Pekanbaru
}

\author{
Laode Burhanuddin $\mathrm{M},{ }^{1 *}$ Suyanto, ${ }^{2} \mathrm{Zulfikar}^{2}$
}

\begin{abstract}
Ergonomics deals with optimization, efficiency, health, safety, and comfort in the workplace. One of this ergonomics principle approach is important for unloading workers in the harbour, because their workplace and work-system have high risk of workplace accidents if the principles of ergonomics is not applied. So, the effectivity, efficiency, productivity, comfort, and health of workers in the harbour need to be maintained and improved with ergonomics approach. This research was held on harbour in Pekanbaru city, with descriptive observasional method to describe risk of work ergonomy caused by bad application of ergonomics at work and musculosceletal symptoms proportion of 19 unloading workers by Nordic Body Map (NBM) questionnaire. The result is all unloading workers (100\%) have musculosceletal injury with various grade of injury. When being observed, none of all unloading workers lift the load with the right method and no special technique had been used by unloading workers to lift the load.
\end{abstract}

Keywords : ergonomy, musculosceletal injury, occupational disease.

Ergonomi secara nyata telah memberi dampak terhadap kehidupan manusia sehari-hari, mulai dari rumah sampai ke tempat kerja. Pendekatan dan evaluasi ergonomi diaplikasikan dalam banyak hal, mulai dari perancangan produk, fasilitas kerja dan tempat kerja dengan sasaran untuk menambah efektivitas, efisiensi dan produktivitas tenaga kerja. Berdasarkan sudut pandang ergonomi, antara tuntutan tugas dan kapasitas kerja harus selalu dalam garis keseimbangan sehingga dicapai performansi kerja yang tinggi. Tuntutan tugas pekerjaan tidak boleh terlalu rendah dan juga tidak boleh terlalu berlebihan. ${ }^{1}$

Menurut Departemen Kesehatan RI penerapan ergonomi di tempat kerja adalah bertujuan agar pekerja pada saat bekerja selalu dalam keadaan sehat, nyaman, selamat, produktif, dan sejahtera. Serta penerapan prinsip-prinsip ergonomi sebagai

\footnotetext{
* Korespondensi : laode_fkur@yahoo.com ${ }^{1}$ KJF Anatomi, Fakultas Kedokteran Universitas Riau

${ }^{2}$ Fakultas Kedokteran Universitas Riau
}

bagian dari Kesehatan dan Keselamatan Kerja (K3) di perusahaan merupakan hal yang sangat penting karena akan mampu meningkatkan kesehatan dan keselamatan tenaga kerja sekaligus meningkatkan produktivitas kerjanya, dengan adanya penerapan ergonomi dalam aktivitas kerja, diharapkan dapat menekan terjadinya kasus-kasus kecelakaan kerja yang selama ini banyak terjadi pada sektor konstruksi, perhubungan darat, laut, dan udara, pertambangan serta sektor lainnya. ${ }^{2}$

Dalam dunia kerja terdapat Undang-Undang yang mengatur tentang ketenagakerjaan yaitu Undang-Undang No.14 tahun 1969 tentang ketentuan-ketentuan pokok tenaga kerja merupakan subyek dan obyek pembangunan. Ergonomi yang bersasaran akhir efisiensi dan keserasian kerja memiliki arti penting bagi tenaga kerja, baik sebagai subyek maupun obyek, tetapi sering kali suatu tempat kerja mengesampingkan aspek ergonomi bagi para pekerjanya, hal ini tentunya sangat merugikan para pekerja itu sendiri. ${ }^{3}$ 
Tingkat kecelakaan kerja dan berbagai ancaman keselamatan dan kesehatan kerja di Indonesia masih cukup tinggi. Berbagai kecelakaan kerja masih sering terjadi dalam proses produksi terutama di sektor jasa konstruksi. International Labour Organization (ILO) menyebutkan bahwa sekitar 2,2 juta jiwa per tahun di seluruh belahan dunia kehilangan nyawa akibat penyakit yang terkait dengan pekerjaan. Berdasarkan laporan ILO, setiap hari terjadi kecelakaan kerja yang mengakibatkan korban fatal sekira 6.000 kasus. Sementara di Indonesia setiap 100.000 tenaga kerja terdapat 20 orang fatal akibat kecelakaan kerja. Tak hanya itu, menurut kalkulasi ILO, kerugian yang harus ditanggung akibat kecelakaan kerja di negara-negara berkembang juga tinggi, yakni mencapai $4 \%$ dari Gross National Product (GNP) Lebih seperempat dari total kecelakaan kerja terjadi berkaitan dengan pekerjaan manual handling. ${ }^{1}$

Untuk pendekatan ergonomi lebih lanjut, TKBM (Tenaga Kerja Bongkar Muat) di pelabuhan merupakan objek penting sebagai pelaksana ergonomi tersebut dikarenakan pekerjaan mereka berkaitan dengan manual handling sehingga memiliki risiko yang tinggi untuk terjadinya kecelakaan kerja. Menurut Silalahi dkk (1991) hampir 25\% kecelakaan di Indonesia yang diderita oleh pekerja adalah akibat mengangkat material secara manual. Pelabuhan yang merupakan tempat yang terdiri dari daratan dan perairan di sekitarnya dengan batas-batas tertentu sebagai tempat kegiatan pemerintahan dan kegiatan ekonomi yang dipergunakan sebagai tempat kapal bersandar, berlabuh, naik turun penumpang atau bongkar muat barang yang dilengkapi dengan fasilitas keselamatan pelayaran dan kegiatan penunjang pelabuhan serta sebagai tempat perpindahan intra dan antar moda transportasi. ${ }^{4}$

Global Competitiveness Report 2011-2012 menyebutkan dari 142 negara, daya saing pelabuhan di Indonesia berada diperingkat ke-103, sedikit meningkat dari tahun sebelumnya yang berada di urutan ke-104. Efektifitas, efisiensi dan produktifitas TKBM di pelabuhan perlu dijaga dan ditingkatkan dengan pendekatan ergonomi. ${ }^{5,6}$

International Labour Organitation (ILO) menyatakan bahwa dengan menerapkan prinsip ergonomi maka masalah yang ada ditempat kerja akan dapat diselesaikan atau dicegah, seperti terjadinya kecelakaan kerja serta menurunnya efektifitas, efisiensi dan produktifitas tenaga kerja itu sendiri. Identifikasi faktor risiko ergonomi dapat dilakukan dengan cara evaluasi lingkungan kerja, evaluasi sistem kerja, evaluasi gangguan kesehatan dengan menggunakan kuesioner Nordic Body Map dan lain-lain. Evaluasi lingkungan kerja bertujuan untuk menilai apakah suatu lingkungan kerja berpotensial untuk menimbulkan gangguan kesehatan ditinjau dari aspek ergonomi. Kuesioner Nordic Body Map bertujuan untuk menilai apakah ada terdapat dampak dari faktor ergonomi kerja terhadap timbulnya keluhan gangguan muskuloskeletal pada pekerja. $^{7}$

\section{METODE}

Disain penelitian ini dilakukan dengan jenis metode penelitian deskriptif observasional, yaitu penelitian yang bertujuan melihat gambaran sikap ergonomi dan proporsi keluhan muskuloskeletal pada TKBM di Pelabuhan Bongkar Muat, Sungai Duku, Kota Pekanbaru. Penelitian ini dilakukan April November 2014. Populasi dalam penelitian ini adalah TKBM di pelabuhan yang berjumlah 19 orang. Penelitian ini dimulai dengan mewawancarai responden, dilanjutkan dengan perekaman dengan video proses pengangkatan beban, kemudian dilakukan penilaian secara tidak langsung pada video apakah cara atau metode angkat yang digunakan para responden sudah benar atau tidak. Lalu untuk melihat batasan dan tindakan atas beban yang diangkat oleh responden, peneliti melakukan observasi atas berat barang yang diangkat serta melihat apakah ada atau tidak tindakan yang sesuai atas berat barang/beban yang diangkat oleh TKBM tersebut. Selanjutnya untuk mengetahui adanya keluhan gangguan muskuloskeletal pada responden, digunakan kuesioner nordic body map. Kuesioner nordic body map adalah kuesioner yang paling sering digunakan untuk melihat keluhan subjektif pada pekerja karena sudah terstandarisasi dan tersusun rapi, dimulai dari leher sampai kaki.

\section{HASIL}

Pada pelabuhan bongkar muat Kota Pekanbaru terdapat 19 responden yang semuanya menjadi sampel pada penelitian ini. Adapun karakteristik responden sebagai berikut: 
Tabel 1. Distribusi frekuensi karakteristik responden berdasarkan jenis kelamin, usia, masa kerja dan adanya pekerjaan sampingan

\begin{tabular}{|c|c|c|c|}
\hline No & Variabel & Frekuensi (n) & Persentase $(\%)$ \\
\hline 1 & $\begin{array}{c}\text { Jenis kelamin } \\
\bullet \quad \text { Laki-laki }\end{array}$ & 19 & 100 \\
\hline 2 & $\begin{aligned} \text { Usia } & \\
\bullet & <30 \\
\bullet & 30-40 \\
\bullet & >40\end{aligned}$ & $\begin{array}{l}8 \\
6 \\
5\end{array}$ & $\begin{array}{l}42,1 \\
31,6 \\
26,3\end{array}$ \\
\hline 3 & $\begin{array}{l}\text { Masa Kerja } \\
\bullet \quad \leq 12 \text { Bulan } \\
\bullet \quad>12 \text { Bulan }\end{array}$ & $\begin{array}{c}0 \\
19\end{array}$ & $\begin{array}{c}0 \\
100\end{array}$ \\
\hline 4 & $\begin{array}{c}\text { Memiliki Pekerjaan Sampingan } \\
\text { - Ya } \\
\text { - Tidak }\end{array}$ & $\begin{array}{c}9 \\
10\end{array}$ & $\begin{array}{l}52,6 \\
47,4\end{array}$ \\
\hline
\end{tabular}

Tenaga kerja bongkar muat bekerja selama $>8$ jam, serta tidak diberlakukan sistem pengaturan pergantian jam kerja pada TKBM di pelabuhan ini. Semuanya bekerja pada waktu yang sama, pagi, siang maupun malam, tergantung jadwal masuknya kapal.

Pada Tabel 1, semua responden memiliki keberagaman dalam hal usia, namun seluruh responden yang berjumlah 19 orang memiliki kategori usia dewasa dan lansia, tidak ada responden yang masuk dalam kategori anak-anak. Jenis kelamin semua respoden yakni laki-laki, tidak ada TKBM wanita yang dijadikan responden pada penelitian ini.

Pada pelabuhan bongkar muat barang ini berlaku sistem jaga/ronda, setiap malamnya 1 orang
TKBM secara bergantian mendapat tugas untuk jaga/ronda di pelabuhan dan bagi yang mendapat tugas ronda tersebut diberi waktu istirahat setengah hari pada besok harinya. Pada penelitian ini dilakukan observasi terhadap sikap tubuh dalam bekerja yang dilakukan TKBM yang mengangkat barang/beban dalam proses bongkar muat dari kapal menuju tempat penyimpanan/gudang pelabuhan maupun menuju ke truk pembawa barang.

Observasi terhadap sikap tubuh dalam mengangkat barang/beban yang dilakukan TKBM ini dilakukan pada 3 periode waktu, yaitu di awal waktu kerja pada saat proses pengangkatan pertama kali dilakukan, pada pertengahan waktu kerja yaitu proses barang sudah berulang-ulang dilakukan, dan pada akhir waktu kerja.

Tabel 2. Distribusi frekuensi sikap tubuh TKBM dalam mengangkat beban/barang berdasarkan periode waktu pengangkatan.

\begin{tabular}{lcccc}
\hline \multicolumn{1}{c}{ Variabel } & \multicolumn{2}{c}{$\begin{array}{c}\text { Cara mengangkat } \\
\text { yang benar }\end{array}$} & \multicolumn{2}{c}{$\begin{array}{c}\text { Cara mengangkat } \\
\text { yang salah }\end{array}$} \\
\cline { 2 - 5 } & Frekuensi & Persentase & Frekuensi & Persentase \\
\hline $\begin{array}{l}\text { Observasi Pertama } \\
\text { (awal waktu kerja) }\end{array}$ & 0 & 0 & 19 & 100 \\
& & & & 100 \\
$\begin{array}{l}\text { Observasi kedua } \\
\text { (Pertengahan waktu } \\
\text { kerja) }\end{array}$ & 0 & 0 & 19 & 100 \\
$\begin{array}{l}\text { Observasi Ketiga } \\
\text { (Akhir waktu kerja) }\end{array}$ & 0 & 0 & 19 & 100 \\
\hline
\end{tabular}


Berdasarkan Tabel 2 dapat dilihat jumlah persentase cara mengangkat yang benar dan cara mengangkat yang salah oleh TKBM dalam mengangkat beban/barang. Hasil observasi didapatkan 100\% TKBM menggunakan cara yang tidak benar/tidak ergonomi dalam mengangkat beban atau suatu barang berdasarkan pengamatan pada periode waktu pengangkatan yakni pengangkatan pada awal waktu kerja, pengangkatan pada pertengahan waktu kerja dan pengangkatan pada akhir waktu kerja.

Tabel 3. Distribusi frekuensi batasan atas beban yang diangkat

\begin{tabular}{cccc}
\hline & Variabel & Frekuensi & Persentase \\
\hline- & $>40 \mathrm{~kg}$ & 0 & 0 \\
- & $\leq 40 \mathrm{~kg}$ & 19 & 100 \\
\hline
\end{tabular}

Pada Tabel 3 dapat disimpulkan bahwa seluruh responden masih mengangkat beban/barang dalam batas yang masih dianjurkan oleh International Labour Organitation (ILO), yaitu batasan angkat pada laki-laki dewasa maksimal 40 $\mathrm{kg}$.

Tabel 4. Distribusi frekuensi keluhan muskuloskeletal responden berdasarkan pengisian kuesioner Nordic

\begin{tabular}{|c|c|c|c|c|c|}
\hline \multirow{3}{*}{$\mathrm{NO}$} & \multirow{3}{*}{ JENIS KELUHAN } & \multicolumn{4}{|c|}{ TINGKAT KELUHAN } \\
\hline & & \multicolumn{2}{|c|}{ SAKIT } & \multicolumn{2}{|c|}{ TIDAK SAKIT } \\
\hline & & Frekuensi & Persentase & Frekuensi & Persentase \\
\hline 1 & Sakit kaku di leher bagian atas & 10 & 52,7 & 9 & 47,3 \\
\hline 2 & Sakit kaku di leher bagian bawah & 7 & 36,8 & 12 & 63,2 \\
\hline 3 & Sakit di bahu kiri & 7 & 36,8 & 12 & 63,2 \\
\hline 4 & Sakit di bahu kanan & 7 & 36,8 & 12 & 63,2 \\
\hline 5 & Sakit di lengan atas kiri & 7 & 36,8 & 12 & 63,2 \\
\hline 6 & Sakit di punggung & 7 & 36,8 & 12 & 63,2 \\
\hline 7 & Sakit lengan atas kanan & 12 & 63,2 & 7 & 36,8 \\
\hline 8 & Sakit pada pinggang & 15 & 78,9 & 4 & 21,1 \\
\hline 9 & Sakit pada panggul & 0 & 0 & 19 & 100 \\
\hline 10 & Sakit pada bokong & 3 & 15,9 & 16 & 84,1 \\
\hline 11 & Sakit pada siku kiri & 7 & 36,8 & 12 & 63,2 \\
\hline 12 & Sakit pada siku kanan & 4 & 21,2 & 15 & 78.8 \\
\hline 13 & Sakit pada lengan bawah kanan & 4 & 21,2 & 15 & 21,2 \\
\hline 14 & Sakit pada lengan bawah kiri & 3 & 15,9 & 16 & 84,1 \\
\hline 15 & Sakit pada pergelangan tangan kanan & 0 & 0 & 19 & 100 \\
\hline 16 & Sakit pada pergelangan tangan kiri & 19 & 100 & 0 & 0 \\
\hline 17 & Sakit pada tangan kiri & 0 & 0 & 19 & 100 \\
\hline 18 & Sakit pada tangan kanan & 0 & 0 & 19 & 100 \\
\hline 19 & Sakit pada paha kiri & 2 & 10,6 & 17 & 89,4 \\
\hline 20 & Sakit pada paha kanan & 2 & 10,6 & 17 & 89,4 \\
\hline 21 & Sakit pada lutut kiri & 2 & 10,6 & 17 & 89,4 \\
\hline 22 & Sakit pada lutut kanan & 3 & 15,8 & 16 & 84,2 \\
\hline 23 & Sakit pada betis kiri & 1 & 5,3 & 18 & 94,7 \\
\hline 24 & Sakit pada betis kanan & 5 & 26,3 & 14 & 73,7 \\
\hline 25 & Sakit pada pergelangan kaki kiri & 1 & 5,3 & 18 & 94,7 \\
\hline 26 & Sakit pada pergelangan kaki kanan & 1 & 5,3 & 18 & 94,7 \\
\hline 27 & Sakit pada kaki kiri & 0 & 0 & 19 & 100 \\
\hline 28 & Sakit pada kaki kanan & 0 & 0 & 19 & 100 \\
\hline
\end{tabular}

Identifikasi keluhan muskuloskeletal dengan pengisian kuesioner Nordic Body Map

Semua responden yang berjumlah 19 orang memiliki keluhan gangguan muskuloskeletal akibat pekerjaan pada bagian tubuh yang berbeda.

\section{Body Map (NBM)}


Pada tabel 4 dapat dilihat, keluhan terbanyak adalah sakit pada pergelangan tangan kiri $(100 \%)$, sebanyak $78,9 \%$ mengalami sakit pada pinggang, $63,2 \%$ mengalami sakit lengan atas kanan dan tidak ada responden yang mengeluhkan sakit pada panggul, pergelangan tangan kanan, tangan kiri, tangan kanan, kaki kiri, dan kaki kanan.

\section{PEMBAHASAN}

\section{Observasi sikap tubuh TKBM dalam bekerja}

Pada penelitian ini dilakukan observasi sikap tubuh TKBM dalam bekerja, tidak terjadi masalah/ kecelakaan kerja pada proses observasi, tetapi yang menjadi perhatian adalah pada metode angkat yang tidak ergonomis. Hasil observasi menunjukkan bahwa semua responden (100\%) tidak menggunakan metode angkat yang benar. Barang yang diangkat berupa kardus yang berisi makanan, barang pecah belah, peralatan rumah tangga, semen, dan sebagainya. Penelitian yang sama juga telah dilakukan Gina A (2009) dengan observasi terhadap 78 orang buruh yang bekerja sebagai TKBM, didapatkan seluruh TKBM tidak menggunakan metode angkat yang ergonomis.

Observasi terhadap sikap tubuh dalam mengangkat barang/beban yang dilakukan TKBM ini dibagi menjadi 3 periode waktu, diharapkan ada perbedaan antara pengangkatan awal (pada saat mulai bekerja) dengan pengangkatan di periode waktu yang lain, peneliti berasumsi jika pengangkatan pertama kali didapatkan metode angkat yang benar, namun sesuai hasil observasi yang sudah dijelaskan diatas bahwa semua responden tidak menggunakan metode angkat yang benar semua periode waktu pengangkatan.

Apabila dalam menyelesaikan pekerjaan orang tidak memerlukan peralatan, bukan berarti ergonomi tidak berlaku. Dalam hal ini ergonomi dapat berlaku, yakni bagaimana mengatur cara atau metode kerja meskipun hanya dengan menggunakan anggota tubuh saja pekerjaan itu dapat terselesaikan dengan efisien tanpa menimbulkan kelelahan. ${ }^{8}$ Berikut adalah prosedur/cara mengangkat beban berat secara ergonomis :

1. Mula-mula berjongkok untuk mencari posisi seimbang dengan kaki setengah terbuka, merapatkan badan kearah benda, pada saat benda akan terangkat punggung harus lurus, dagu diangkat agar kepala dan badan tidak cenderung membungkuk atau sedapat mungkin tegak lurus.

2. Langkah mengangkat, pegangan tangan harus kuat dan mengerahkan tenaga yang ditanggung oleh tulang dan otot, tegakkan dan luruskan kaki, maka terangkatlah benda tersebut.

3. Langkah terakhir, meluruskan badan bagian atas sehingga lurus dengan kaki dan sedapat mungkin tegak lurus dengan lantai.

Kondisi jalan yang menjadi jalur untuk dilalui responden saat proses kerja berlangsung juga tidak begitu baik, terjal, tidak rata dan tidak disemenisasi. Namun proses semenisasi baru direncanakan oleh pemilik pelabuhan dalam waktu dekat. Selain metode angkat yang tidak benar yang digunakan oleh seluruh responden, juga jalanan yang terjal dan tidak rata cendrung menjadi risiko terjadinya kecelakaan kerja.

\section{Batasan atas beban yang diangkat}

Batasan angkat untuk TKBM dibuat dalam rangka untuk menciptakan suasana kerja yang aman dan sehat. Pada penelitian ini dilakukan observasi terhadap batasan atas beban yang diangkat para responden, responden yang berjumlah 19 orang ini mayoritas memiliki umur yang masih dikelompokkan dalam kategori dewasa, namun ada juga yang sudah termasuk lansia yakni 1 orang responden yang berusia 61 tahun, tentu responden yang sudah lansia ini tidak layak lagi untuk bekerja karena cendrung mempunyai resiko kecelakaan kerja yang besar. Untuk batasan angkat yang dianjurkan International Labour Organitation (ILO) adalah sebagai berikut:

1. Laki-laki dewasa $40 \mathrm{~kg}$

2. Wanita dewasa $15-20 \mathrm{~kg}$

3. Laki-laki (16-18 tahun) $15-20 \mathrm{~kg}$

4. Wanita (16-18 tahun) $12-15 \mathrm{~kg}$

Pada penelitian ini seluruh responden masuk dalam kategori laki-laki dewasa yang maksimal batasan angkatnya yakni seberat $40 \mathrm{~kg}$, seluruh responden masih mengangkat beban dalam batasan yang telah dianjurkan oleh International Labour Organitation (ILO). Batasan angkat ini membantu mengurangi rasa nyeri dan ngilu pada tulang belakang dan mengurangi resiko ketidaknyamanan kerja. ${ }^{4}$ 


\section{Identifikasi keluhan muskuloskeletal dengan pengisian kuesioner Nordic Body Map}

Pada penelitian ini dilakukan wawancara langsung tentang keluhan muskuloskeletal kepada seluruh responden dengan bantuan kuesioner Nordic Body Map. Keluhan muskuloskeletal ini timbul biasanya setelah responden mengangkat barang dengan frekuensi yang sering dan dengan beban yang berat pada setiap harinya jika mereka bekerja. Lokasi keluhannya yaitu pada leher bagian atas, leher bagian bawah, bahu kiri, bahu kanan, lengan atas kiri, lengan atas kanan, punggung, pinggang, bokong, siku kiri, siku kanan, lengan bawah kanan, lengan bawah kiri, paha kiri, paha kanan, lutut kiri, lutut kanan, betis kiri, betis kanan, pergelangan kaki kiri dan pergelangan kaki kanan. Responden mengalami keluhan pada kedua sisi tubuhnya, hal ini menandakan kedua sisi tubuh menopang beban yang sama.

Keluhan tersebut menyebabkan responden tidak dapat bekerja secara optimal karena terjadinya fatigue, kondisi kelelahan otot ini dapat disebabkan oleh kontraksi otot (isotonik dan isometrik) yang berlebihan dalam jangka waktu yang cukup lama. ${ }^{9}$ Kelelahan otot terjadi jika otot yang beraktivitas tidak lagi dapat berespons terhadap rangsangan dengan derajat kontraksi yang sama. Kelelahan otot adalah suatu mekanisme pertahanan yang melindungi otot agar otot tidak mencapai titik dimana ATP tidak lagi dapat diproduksi. Pada kontraksi isotonik tegangan otot tidak berubah sedangkan panjang otot berubah, pada kontraksi isometrik otot tidak dapat memendek sehingga terbentuk tegangan dengan panjang otot tetap. Proses-proses internal yang sama terjadi baik pada kontraksi isotonik maupun isometrik yakni eksitasi otot mengaktifkan proses kontraktil pembentuk tegangan, jembatan silang mulai bersiklus dan pergeseran filamen memperpendek sarkomer yang meregangkan komponen seri elastik untuk menghasilkan gaya ditulang tempat insersi otot. ${ }^{10}$

Sebagian besar keluhan kelelahan disebabkan oleh ketidakmampuan proses kontraksi dan metabolik otot untuk terus berkontraksi dengan kekuatan yang sama dan akan menurun setelah aktivitas otot mengurangi kontraksi otot yang lainnya. ${ }^{11}$ Pada saat mengangkat beban, dapat dilihat responden pertama mengalami fleksi bahu, fleksi siku, supinasi lengan bawah, fleksi pergelangan tangan, fleksi/ekstensi leher serta fleksi punggung sehingga terdapatnya tumpuan beban pada pinggang, dengan demikian otototot yang rentan mengalami cedera adalah m.sternocleidomastoideus, m.deltoideus, m.trapezius, m.brachialis, m.biceps brachii, m.triceps brachii, m.brachioradialis, m.pronator teres, m.pronator quadratus, m.extensor carpi ulnaris, m.coracobrachialis, m.latissimus dorsi, m.supinator, m.anconeus, m.erector spine, dan pada articulatio cubiti. Pada otot-otot pada eksremitas bawah yang dominan berkontraksi dan rentan mengalami cedera adalah m.adductor magnus, m.adductor longus, m.quadriceps femoris, m.biceps femoris dan pada articulatio genus. $^{12}$

Pada saat membawa beban/barang, dapat dilihat responden mengalami fleksi pada siku, supinasi lengan bawah, fleksi pergelangan tangan, fleksi leher, fleksi bahu dan fleksi tungkai, dengan demikian otot-otot yang yang rentan mengalami cedera adalah m.sternocleidomastoideus, m.deltoideus, m.trapezius, m.brachialis, m.biceps brachii, m.triceps brachii, m.brachioradialis, m.pronator teres, m. pronator quadratus, m.extensor carpi ulnaris, m.coracobrachialis, m.latissimus dorsi, m.supinator, m.anconeus, $m$.erector spine, dan pada articulatio cubiti sedangkan otot-otot pada eksremitas bawah yang dominan berkontraksi dan rentan mengalami cedera adalah m.tibialis anterior, m.gastrocnemius, m.soleus, m.gluteus maximus, m.plantaris dan pada articulatio talocruraris. ${ }^{12}$

Keluhan muskuloskeletal yang timbul disebabkan oleh kontraksi otot yang berlebihan, otototot berperan dominan pada saat mengangkat dan membawa beban/barang oleh TKBM adalah m.sternocleidomastoideus, m.deltoideus, m.trapezius, m.brachialis, m.bicepsbrachii, m.triceps brachii, m.coracobrachialis, m.brachioradialis, m.anconeus, m.supinator, m.pronator teres, m.pronator quardatus, m.extensor carpi ulnaris, m.gluteus maximus, m.adductor magnus, m.adductor longus, m.quadriceps femoris, m.biceps femoris, m.tibialis anterior, m.gastroenemius dan m.soleus, m.erector spine, m.latissimus dorsi, m.plantaris serta sendi-sendi yang terlibat yakni a.cubiti, a.genus dan a.talocruraris. ${ }^{12}$ Responden mengeluhkan sakit pada otot-otot tersebut, hal ini dapat terjadi selain karena kontraksi yang berlebihan, juga dapat disebabkan oleh postur kerja yang kurang sesuai, seperti keluhan pada betis, ini merupakan keluhan m.gastrocnemius ${ }^{13.14}$ 


\section{SIMPULAN}

Keseluruhan responden adalah berjenis kelamin laki-laki, berusia terbanyak pada rentang umur 3040 tahun, dengan masa kerja yang sama yakni sudah lebih dari 12 bulan (100\%). Selain bekerja sebagai TKBM beberapa responden ada yang memiliki pekerjaan sampingan. Semua responden tidak menggunakan metode angkat yang benar $(100 \%)$. Seluruh responden masih mengangkat beban/barang dalam batas yang masih dianjurkan oleh international labour organitation (ILO). Tidak ada tindakan khusus yang dilakukan seluruh responden atas beban yang mereka angkat. Wawancara dengan bantuan kuesioner nordic body map didapatkan seluruh responden memiliki keluhan gangguan muskuloskletal dengan gradasi yang bervariasi, persentase nyeri yang cukup besar yakni pada bagian pinggang/ punggung bagian bawah sebesar $68,4 \%$.

\section{DAFTAR PUSTAKA}

1. Tarwaka, solichul HA, bakri, sudiajeng L. Ergonomi untuk keselamatan, kesehatan kerja dan produktivitas. Uniba press; 2004.

2. Pusat Humas Kemnakertrans. Keselamatan dan Kesehatan Kerja (K3 ) (serial online).(dikutip 1 oktober 2014). Available from: URL: HYPERLINK http://www.depnakertrans.go.id/ news.html,960,umum

3. Undang-undang Republik Indonesia Nomor 17 tahun 2008 tentang Pelayaran.
4. Suma'mur. Ergonomi untuk produktivitas kerja. Jakarta: Cermin Dunia Kedokteran; 2007. p. 154

5. Schwab K, Martin XS, Robert G. The global competitiveness report. 2011-2012

6. Columbia University. Chief advisor of the centre for global competitiveness and performance; 2011

7. Adhiyati S. Pengaruh stimulus kutaneus slowstroke back massage terhadap intensitas nyeri pada penderita low back pain (LBP) di kelurahan aek gerger sidodadi. Medan: Universitas Sumatera Utara; 2011.

8. Notoatmodjo S. Ilmu kesehatan masyarakat (Prinsip-Prinsip Dasar). Jakarta: PT.Asdi Mahasatya.2003

9. Notoatmodjo S. Kesahatan masyarakat ilmu dan seni. Jakarta : PT. Rineka Cipta.2007

10.Lauralee S. Fisiologi manusia dari sel ke sistem. In: Yesdelita N, editor. 6th ed. Jakarta: EGC; 2011.

11. Rozy F. Identifikasi faktor resiko ergonomi kerja pada petugas pendorong brankar di rumah sakit x. Pekanbaru:Fakultas Kedokteran Universitas Riau.2013

12.Putz R, Pabst R. Sobotta Atlas Anatomi Manusia Jilid 1 \& 2. Tabel otot, sendi dan saraf. 22th Ed. jakarta. EGC:2006.

13.Putz R, Pabst R. Sobotta atlas anatomi manusia Jilid 1. 22th ed. Jakarta: EGC; 2006. p. 11-209.

14.Putz R, Pabst R. Sobotta atlas anatomi manusia Jilid 1. 22th ed. Jakarta: EGC; 2006. p. 26-326. 